\title{
Prospective double-blind clinical trial evaluating the effectiveness of bromelain in the third molar extraction postoperative period
}

\author{
María del Carmen de la Barrera-Núñez ${ }^{1}$, Rosa-María Yáñez-Vico ${ }^{2}$, Antonio Batista-Cruzado ${ }^{1}$, Jean-Michel \\ Heurtebise-Saavedra ${ }^{1}$, Raquel Castillo-de Oyagüe ${ }^{3}$, Daniel Torres-Lagares ${ }^{4}$
}

${ }^{1}$ DDS, Departament of Stomatology. School of Dentistry. University of Seville

${ }^{2}$ DDS, PhD, Departament of Stomatology. School of Dentistry. University of Seville

${ }^{3}$ DDS, PhD, Departament of Stomatology. School of Dentistry. University Complutense

${ }^{4}$ DDS, PhD, Professor of Oral Surgery. Department of Stomatology. University of Seville

Correspondence:

School of Dentistry of Seville

C/ Avicena s/n 41009. Seville. Spain

danieltl@us.es

Received: 03/02/2013

Accepted: $12 / 07 / 2013$

\begin{abstract}
de la Barrera-Núñez MC, Yáñez-Vico RM, Batista-Cruzado A, Heurtebise-Saavedra JM, Castillo-de Oyagüe R, Torres-Lagares D. Prospective double-blind clinical trial evaluating the effectiveness of bromelain in the third molar extraction postoperative period. Med Oral Patol Oral Cir Bucal. 2014 Mar 1;19 (2):e157-62.

http://www.medicinaoral.com/medoralfree01/v19i2/medoralv19i2p157.pdf
\end{abstract}

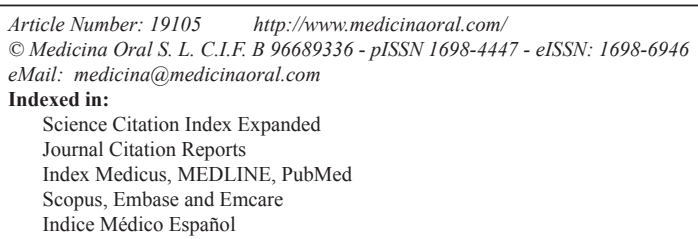

Indice Médico Español

\begin{abstract}
Objectives: To evaluate the anti-inflammatory and analgesic effect of Bromelain (pineapple extract) administered orally in the postoperative after extraction of impacted lower molars.

Study Design: This is a prospective, placebo-controlled, unicentric, double-blind study; the sample size was 34 patients. The pre and postoperative outcomes, evaluated on the third (D3) and eighth day (D8), included inflamtion, pain and oral aperture, as well as the need for analgesics. One group received bromelain $150 \mathrm{mg}$ per day for three days and $100 \mathrm{mg}$ on days 4 to 7 . The other group received placebo in the same dosage. All outcomes werrecorded quantitatively and analyzed with the Mann-Whitney U test for independent samples.

Results: Although there were no statistically significant differences between the treatment groups, a trend towards less inflammation and improved oral aperture was observed in the group that received bromelain, compared to the group that received placebo. This trend can be attributed completely to random reasons, since there is no statistical difference in the results.

Conclusions: Further studies are necessary to analyze different administration patterns and doses of bromelain for the use in the postoperative of impacted third molars.
\end{abstract}

Key words: Tooth extraction, third molar, postoperative period, bromeline, clinical study.

\section{Introduction}

Bromelain (pineapple enzyme, Ananas comasus) is an aqueous extract obtained from the stem and fruit of the pineapple plant that contains high levels of proteolytic enzymes and which composition varies depending on the source and purification method $(1,2)$. Bromelain directly influences pain mediators such as bradykinin (3), although its analgesic properties are closely linked to its anti-inflammatory properties $(4,5)$. It has beenshownthat this fibrinolytic agent promotes reabsorption 
of edema in the blood circulation (6); it reduces swelling, bruising, pain, and healing time after trauma and surgical procedures (5). Evidence has shown that bromelain digests fibrin, thus allowing the elimination of edema (7). Indirectly, bromelain increases the time required for the conversion of prothrombin into thrombin, and thus activating plasminogen into plasmin; by these means, it prevents the formation of fibrin (7). All these cause a reduction in vascular permeability. In addition, bromelain inhibits the synthesis of pro-inflammatory prostaglandins, particularly PGE2 (8).

The most common postoperative complications after the extraction of an impacted wisdom tooth are a direct consequence of the inflammatory response to the surgical procedure (9) and include pain, inflammation and difficulty opening the mouth (10). Generally this response is controlled with the surgical technique (11-16) and mainly with pharmacological anti-inflammatory measures $(17,18)$.

The purpose of our study was to assess the effect of bromelain on inflammation, pain perception, and trismus,after the extraction of an impacted lower third molar, using a prospective double-blind clinical trial.

\section{Material and Methods}

-Subjects

34 healthy subjects,patients from the Faculty of Odontology of the University of Seville (Spain) who needed the extraction of a lower third molar, were consecutively selected for the study. All the extractions were classified with a Koerner index (19) 5-6 (moderately difficult). This way, we excluded all candidates who met any exclusion criteria: allergy to any of the components used in the study; contraindication for the administration of adrenaline; psychiatric treatment; pregnancy or lactation; coagulation disorders or any treatment that may alter it; antibiotic treatment, analgesics or antiinflammatories used on the four days prior to the intervention; active periodontitis; smoking more than ten cigarettes per day. The eligible patients were informed of the study and gave their consent. The University of Seville Research Ethics Committeeindependently approved the procedure.

-Surgical Procedure

Articaine 4\% with adrenaline 1:100.000was used as anesthetic. In all cases a bayonet incision with vertical discharge was performed on the mesial half of the second molar;a mucoperiosteal flap was lifted, and osteotomy was performed with a number eight tungsten carbide bur mounted on a hand piece; the extraction was completed by drift. Odontosection was performed with turbine and fissure bur, when needed.

The material used to suture the surgical wound was black braided silk 4/0, needle holder, toothless Adson forceps and scissors. The same operator performed all the inter- ventions, and the same surgical material was used. The surgical protocol was not modified in any case.

-Pharmacological Treatment

It was decided to include a total of 40 patients in the study (20 per group), considering that the difference in inflammation marked on the third postoperative day would be $1.25 \mathrm{~cm}$ between the two groups, and estimating a variance of 2, with an alpha error of 0.05 (bilateral) and a beta error of 0.2 .

For various reasons, the analysis was limited to 34 subjects (Fig. 1). After maintaining the same alpha and beta errors, this sample size should be enough to identify a $1.4 \mathrm{~cm}$ difference in swelling between the two groups, marked on the third postoperative day, and estimating a variance of 2 .

The analysis was performed following a random and independent division on the side (right or left) into two groups: Test group $(\mathrm{n}=16)$ and Control group $(\mathrm{n}=18)$ (Fig. 1). All patients received the following medications: a) amoxicillin / clavulanate acid $875 / 125 \mathrm{mg}$ every 8 hours for 7 days, b) Paracetamol $500 \mathrm{mg}$ (as first step rescue); Nolotil ® 575 mg (Boehringer Ingelheim, Spain, SA Sant Cugat del Valles, Barcelona) (as second step rescue). To assess the effect of bromelain, the tablets used in this trialcontained $100 \mathrm{nkat}$, equivalent to $50 \mathrm{mg}$ of Ananas stem. The Test group was administered a regimen of three tablets per day during the first three days and two tablets per day from the fourth to the seventh day. The Control Group was given placebo, three tablets a day for the first three days and two tablets a day from the fourth to the seventh day. When corticosteroid administration was required, following tooth extraction with a large osteotomy and / or long duration (over 30 minutes), the patient was excluded from the study due to the increased inflammation that both produce. In our study, two patients were excludedfor this reason; and two patients were excluded due to the administration of anti-inflammatory drugs that were not included in the study.

The randomization was performed through a randomized list generated on a computer by the company Rothapharm, which used this randomization to prepare the pharmacological blisters of placebo or medication, with a blind design that did not allow the identification of any of them without access to the list; this access was only at the end of the study to analyze the data.

-Assessment of postoperative pain

Postoperative pain was calculated using a Visual Analogue Scale (VAS) of $10 \mathrm{~cm}$ in length, that is, a straight line with endpoints representing the sensation limits: no pain in one end and unimaginable pain at the other (20). The patient registered the pain values presented at the beginning of the study, on day 3 (D3) and on day 8 (D8) postoperatively. We used a range of 0-10 (cm), with 0 beingabsolute absence of pain and 10 the maximum degree of pain. 


\section{CONSORT 2010 Flow Diagram}

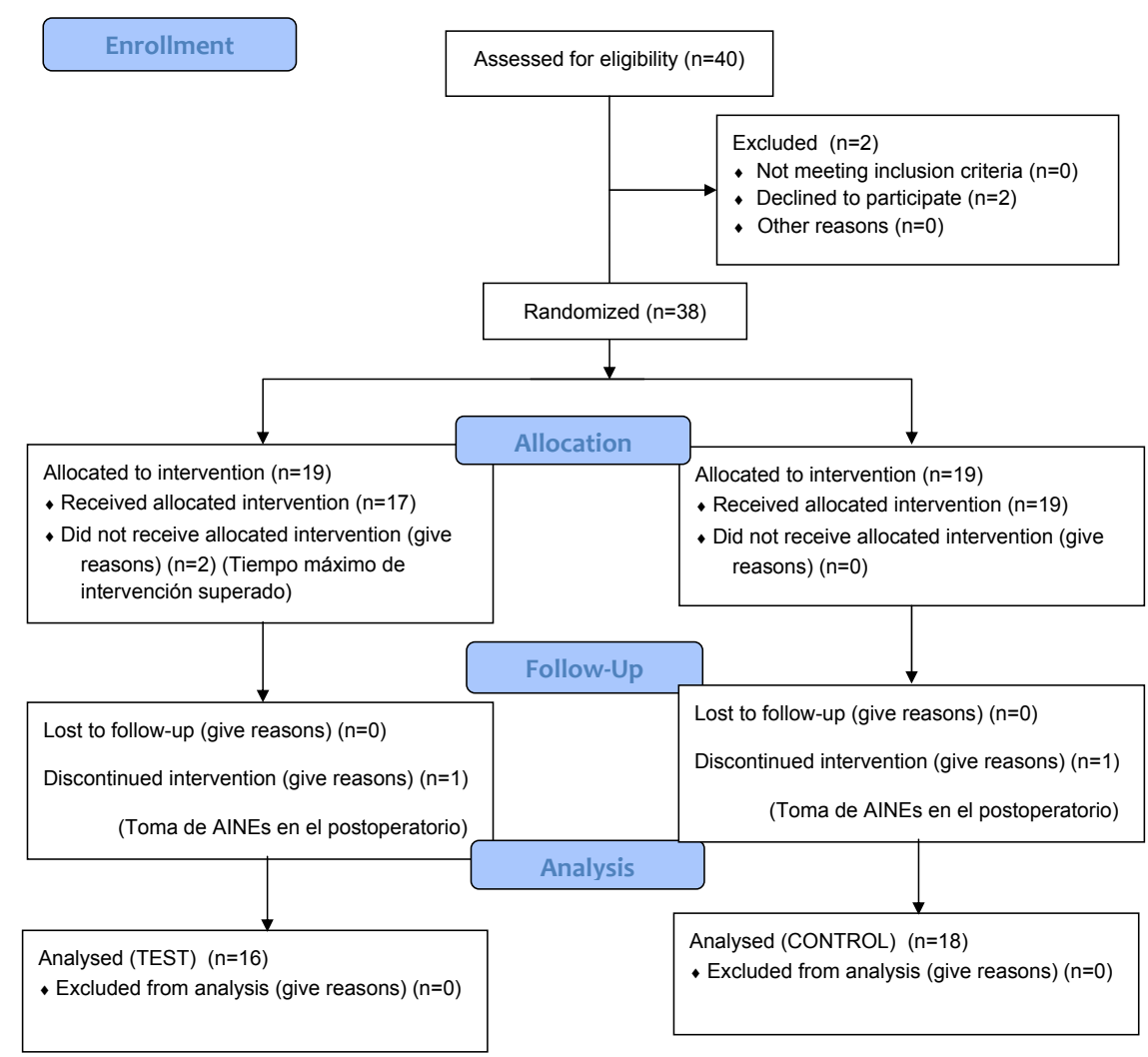

Fig. 1. Consort flow chart.

-Assessment of postoperative facial swelling

Postoperative swelling was calculated using a Visual Analogue Scale (VAS) of $10 \mathrm{~cm}$ in length, that is, a straight line which endpoints represent the sensation limits: no swelling at one end and maximum swelling at the other (20). The patient registered the swelling values experienced at the beginning of the study (D0), on day 3 (D3) and on day 8 (D8) postoperatively. We used a range of $0-10(\mathrm{~cm})$, with 0 being absolute absence of swelling and 10 the maximum degree of swelling.

-Assessment of postoperative trismus

The degree of trismus was assessed by measuring the interincisal distance before surgery (D0), on the 3rd (D3), and 8th (D8) days postoperatively, with a specific ruler for oral aperture measurement (Therabite $\AA$ ). The results are expressed in $\mathrm{mm}$ (Fig. 2).

-Statistical analysis

The data was analyzed using SPSS 17.0 software for Windows (LEAD Technologies, USA). Data analysis consisted of descriptive analysis (mean and standard deviation) of the quantitative variables (age, inflammation, pain and aperture). The differences between the two groups for each one of the variables was performed using the Mann-Whitney $U$ test for independent samples with significant differences if $\mathrm{p}<0.05$.

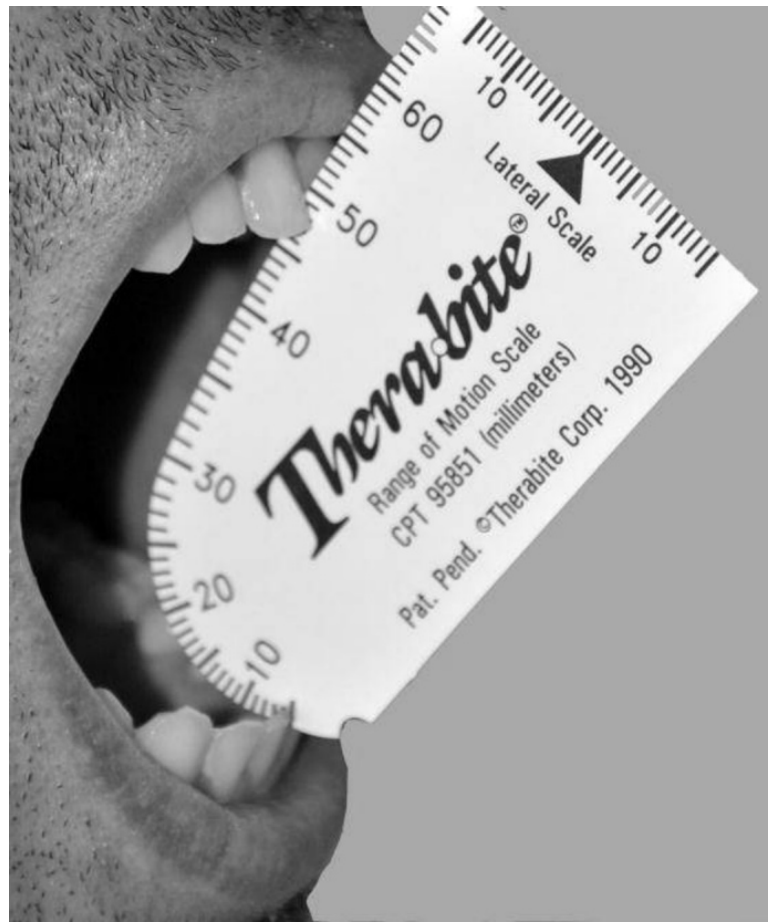

Fig. 2. Quantification method of oral aperture from mesial-incisal angle of lower central incisor to mesial-incisal angle of maxillary central incisor. 


\section{Results}

The total number of patients studied was 17 men and 17 women with a mean age of $23.82 \pm 3.9$ years. In the control group 10 men and 7 women were treated, with an average age of $24.67 \pm 4.2$ years. In the experimental group 6 men and 11 womenwere treated, with a median age of $22.88 \pm 3.6$ years. Differences in age in both groups were not significant ( $\mathrm{p} \geq 0.05$ ).

Preoperatively, the measurement of swelling, pain and aperture in both groups was similar, except for the inflammation which was slightly higher in the experimental group, although no statistically significant differences existed $(\mathrm{p}<0.05)$ in any of them (Table 1).

Table 1 shows the results of the comparison between the control group and the test group on days 3 and 8 , in the different postoperative outcomes. No significant differences were observed in the assessment of pain between the two treatment groups.
Regarding measurement of the oral aperture, one can see that after D3 and specifically in the evaluation at the end of treatment on D8, there is a tendency to an increased aperture ( $3 \mathrm{~mm}$ more then the average) in the group receiving bromelain, although the results were not significant.

The biggest effect of bromelain was observed in inflammation. Patients in the bromelain group, started from a slightly higher swelling values and at the end treatment, there was a slight tendency to a reduction in inflammation $(0.65 \pm 0.6$ vs. $0.88 \pm 0.8)$, not reaching statistical or clinical significance.

Regarding the postoperative use of analgesic medications by patients, there was an increase in the administration between days 1 and 3 , after which there was a progressive decrease (Fig. 3).When comparing both study groups, we found no significant differences in the use of medication during the first eight postoperative days (although it was slightly lower in the control group).

Table 1. Preoperative (D0), and postoperative measurements (D3 = Day 3; D8 = day 8) in $\mathrm{mm}$ (mean \pm d.e) in both study groups, comparisons by Mann-Whitney U test.

\begin{tabular}{|l|l|c|c|c|}
\hline \multicolumn{2}{|c|}{ Variables } & TestGroup & ControlGroup & $p$ \\
\hline Pain & D0 & $0,281 \pm 0,19$ & $0,222 \pm 0,08$ & N.S. \\
\hline & D3 & $2,27 \pm 2,5$ & $2,00 \pm 1,6$ & N.S. \\
\hline & D8 & $0,50 \pm 0,6$ & $0,72 \pm 0,5$ & N.S. \\
\hline Aperture & D0 & $51,75 \pm 1,1$ & $51,67 \pm 1,7$ & N.S. \\
\hline & D3 & $37,88 \pm 10,7$ & $37,78 \pm 8,4$ & N.S. \\
\hline & D8 & $46,63 \pm 8,0$ & $43,72 \pm 9,2$ & N.S. \\
\hline Inflammation & D0 & $0,688 \pm 0,35$ & $0,250 \pm 0,14$ & N.S. \\
\hline & D3 & $4,18 \pm 2,810$ & $5,19 \pm 2,901$ & N.S. \\
\hline & D8 & $0,65 \pm 0,651$ & $0,88 \pm 0,814$ & N.S. \\
\hline
\end{tabular}

N. S. = not significant, $\mathrm{p} \geq 0.05$.

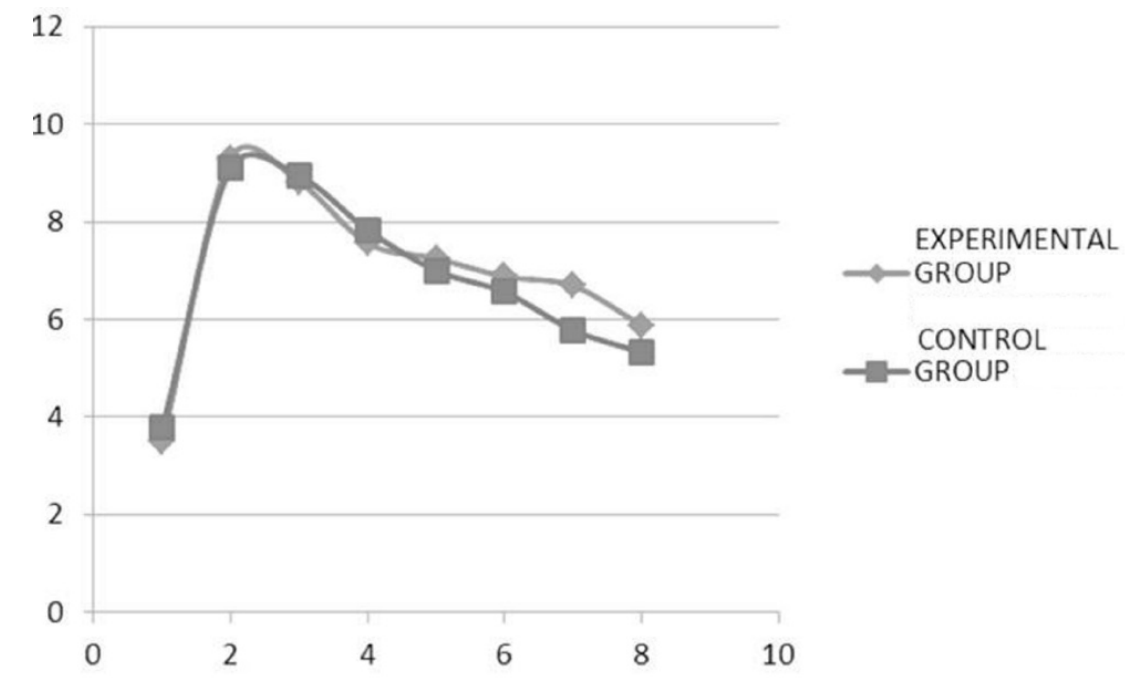

Fig. 3. Quantification method of oral aperture from mesial-incisal angle of lower central incisor to mesial-incisal angle of maxillary central incisor. 


\section{Discussion}

Several studies support the usefulness of orally administered bromelain to reduce pain and swelling after certain surgical procedures $(4,5)$ due to a decreased level of certain pain mediators and vascular phenomena associated with acute inflammation $(3,6)$.

Proteases, such as bromelain, act at specific points on the cell surface of the inflammatory component, specifically where their receptors are found, generating and / or destroying receptor agonists and activating and deactivating them, so they contribute significantly in the signal transduction mechanism of the inflammation. However, this effect can be highly variable depending on the different levels of expression of these receptors, not only in different individuals, but also in different tissues of the same individual (21).

Most of the published studies suggest various types of mechanisms by which proteases, including bromelain, can decrease inflammation. Among them the most prominent are:

-Favoring the return of the interstitial fluid and inflammatory component cells into the bloodstream, and thus decreasing the swelling of the area (22)

-Decreasing the biosynthesisof plasmacinins and proinflammatory prostaglandins PGE2, PGF2 (23)

In our study we have evaluated the efficacy of bromelain in inflammation, pain and degree of oral aperture after the extraction of a lower third molar. Our results are consistent with those obtained by Hozt et al. (24) who evaluated the anti-inflammatory effect of bromelain after the extraction of third molars administering bromelain $80 \mathrm{mg} 3$ times a day for 6 days. In our study we used an oral administration of $150 \mathrm{mg}$, whereas Hozt et al. used $240 \mathrm{mg}$. According to the published results, the administration of $150 \mathrm{mg}$ a day does not seem to be the most effective regimen; or at least it is less effective than the one used by Hozt et al.

Although the results obtained were similar between the two groups regarding pain and inflammation, they (24) obtained a reduced need for analgesic intake in the group that was administered bromelain. This last fact has not been confirmed in our study, as the use of medication in both groups was very similar.

On the other hand, Inchigolo et al. (25) compared the use of bromelain ( $40 \mathrm{mg}$ every 6 hours for 6 days) with ketoprofen (100mg every 12 hours for six days, and found no differences between them. Therefore, they concluded that bromelain is as effective as an NSAID in the treatment of postoperative inflammation.

These differences between studies and the different anti-inflammatory effects obtained may be due largely to a lack of knowledge of the effective dosage administration of bromelain indicated for postoperative inflammation in the extraction of third molars. Although further studies are required in this regard and various tests support the dose-dependent decrease in inflammation with bromelain (26), the analysis of these results seem to indicate a better response to third molar postoperative inflammation with lower doses but less spaced in time (25), than higher doses (150mg) at longer intervals (24 hours), as is the case in this study.

In summary and based on the results obtained, we can conclude that:

- The oral administration of bromelain may have beneficial effects in the control of postoperative inflammation and pain of impacted third molars, using an appropriate dose regimen, although this study has not highlighted these potential benefits.

- Further studies are needed to investigate the hypothesis that different dosing regimens of bromelain may be associated with a greater anti-inflammatory effect in the postoperative management of impacted third molars.

\section{References}

1. Onken JE, Greer PK, Calingaert B, Hale LP. Bromelain treatment decreases secretion of pro-inflammatory cytokines and chemokines by colon biopsies in vitro. ClinImmunol. 2008;126:345-52.

2. Hale LP, Chichlowski M, Trinh CT, Greer PK. Dietary supplementation with fresh pineapple juice decreases inflammation and colonic neoplasia in IL-10-deficient mice with colitis. Inflamm Bowel Dis. 2010;16:2012-21.

3. Aiyegbusi AI, Duru FI, Anunobi CC, Noronha CC, Okanlawon AO. Bromelain in the early phase of healing in acute crush Achilles tendon injury.Phytother Res. 2011;25:49-52.

4. Brien S, Lewith G, Walker A, Hicks SM, Middleton D. Bromelain as a Treatment for Osteoarthritis: a Review of Clinical Studies. Evid Based Complement Alternat Med. 2004;1:251-7.

5. MacKay D, Miller AL. Nutritional support for wound healing. Altern Med Rev. 2003;8:359-77.

6. Maurer HR. Bromelain: biochemistry, pharmacology and medical use. Cell Mol Life Sci. 2001;58:1234-45.

7. TaussigSJ. The mechanism of the physiological action of bromelain. Med Hypotheses. 1980;6:99-104.

8. Gaspani L, Limiroli E, Ferrario P, Bianchi M. In vivo and in vitro effects of bromelain on PGE2 and SP concentrations in the inflammatory exudate in rats. Pharmacology. 2002;65:83-86.

9. McGrath C, Comfort MB, Lo EC, Luo Y. Changes in life quality following third molar surgery-the immediate postoperative period. Br Dent J. 2003;194:265-8

10. Oginni FO, Ugboko VI, Assam E, Ogunbodede EO. Postoperative complaints following impacted mandibular third molar surgery in Ile-Ife, Nigeria. SADJ. 2002;57:264-8.

11. Kirtiloğlu T, Bulut E, Sümer M, Cengiz I. Comparison of 2 flap designs in the periodontal healing of second molars after fully impacted mandibular third molar extractions. J Oral Maxillofac Surg. 2007;65:2206-10.

12. Kim HR, Choi BH, Engelke W, Serrano D, Xuan F, Mo DY. A comparative study on the extractions of partially impacted mandibular third molars with or without a buccal flap: a prospective study. J Oral MaxillofacSurg. 2011; 69:966-70.

13. Freudlsperger C, Deiss T, Bodem J, Engel M, Hoffmann J. Influence of lower third molar anatomic position on postoperative inflammatory complications. J Oral Maxillofac Surg. 2012;70:1280-5.

14. Goyal M, Marya K, Jhamb A, Chawla S, Sonoo PR, Singh V, et al. Comparative evaluation of surgical outcome after removal of impacted mandibular third molars using a Piezotome or a conventional handpiece: a prospective study. Br J Oral Maxillofac Surg. $2012 ; 50: 556-61$.

15. Barone A, Marconcini S, Giacomelli L, Rispoli L, Calvo JL, Cov- 
ani $\mathrm{U}$. A randomized clinical evaluation of ultrasound bone surgery versus traditional rotary instruments in lower third molar extraction. J Oral Maxillofac Surg. 2010;68:330-6.

16. Osunde OD, Saheeb BD, Adebola RA. Comparative study of effect of single and multiple suture techniques on inflammatory complications after third molar surgery.J Oral Maxillofac Surg. 2011;69:971-6.

17. Sierra Rebolledo A, Delgado Molina E, BeriniAytís L, Gay Escoda C. Comparative study of the anesthetic efficacy of $4 \%$ articaine versus $2 \%$ lidocaine in inferior alveolar nerve block during surgical extraction of impacted lower third molars. Med Oral Patol Oral Cir Bucal. 2007;12:E139-44.

18. Bjørnsson GA, Haanaes HR, Skoglund LA. A randomized, double-blind crossover trial of paracetamol $1000 \mathrm{mg}$ four times daily vs ibuprofen $600 \mathrm{mg}$ : effect on swelling and other postoperative events after third molar surgery. Br J ClinPharmacol. 2003;55:405-12.

19. Koerner KR. The removal of impacted third molars.Principles and procedures. Dent Clin North Am. 1994;38:255-78.

20. Scott J, Huskisson EC. Graphic representation of pain.Pain 1976;2:175-84

21. Ossovskaya VS, Bunnet NW. Protease-activated receptors: contribution to physiology and disease Physiol Rev 2004;84:579-621.

22. Smyth RD, Moss JN, Brennan JC. Biochemical studies on the resolution of experimental inflammation in animals treated with bromelaínExp Med Surg 10967;25:229-235.

23. Cirelli MG. Clinical experience with bromelain in proteolitic enzyme therapy of inflammation and edema Med times 1964;92:919. 922.

24. Hotz G, Frank T, Zöller J, Wiebelt H. Antiphlogistic effect of bromelaine following third molar removal. DtschZahnarztl Z 1989;44:830-2.

25. Inchingolo F, Tatullo M, Marrelli M, Inchingolo AM, Picciariello $\mathrm{V}$, Inchingolo AD, et al. Clinical trial with bromelain in third molar exodontia. Eur Rev Med Pharmacol Sci. 2010;14:771-4.

26. Gläser D, Hilberg T. The influence of bromelain on platelet count and platelet activity in vitro.Platelets. 2006;17:37-41. 